NASA/TM-2000-209810

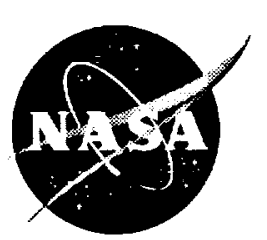

\title{
The NASA Aviation Safety Program: Overview
}

Jaiwon Shin

Glenn Research Center, Cleveland, Ohio 
Since its founding, NASA has been dedicated to the advancement of aeronautics and space science. The NASA Scientific and Technical Information (STI) Program Office plays a key part in helping NASA maintain this important role.

The NASA STI Program Office is operated by Langley Research Center, the Lead Center for NASA's scientific and technical information. The NASA STI Program Office provides access to the NASA STI Database, the largest collection of aeronautical and space science STT in the world. The Program Office is also NASA's institutional mechanism for disseminating the results of its research and development activities. These results are published by NASA in the NASA STI Report Series, which includes the following report types:

- TECHNICAL PUBLICATION. Reports of completed research or a major significant phase of research that present the results of NASA programs and include extensive data or theoretical analysis. Includes compilations of significant scientific and technical data and information deemed to be of continuing reference value. NASA's counterpart of peerreviewed formal professional papers but has less stringent limitations on manuscript length and extent of graphic presentations.

- TECHNICAL MEMORANDUM. Scientific and technical findings that are preliminary or of specialized interest, e.g., quick release reports, working papers, and bibliographies that contain minimal annotation. Does not contain extensive analysis.

- CONTRACTOR REPORT. Scientific and technical findings by NASA-sponsored contractors and grantees.
- CONFERENCE PUBLICATION. Collected papers from scientific and technical conferences, symposia, seminars, or other meetings sponsored or cosponsored by NASA.

- SPECIAL PUBLICATION. Scientific, technical, or historical information from NASA programs, projects, and missions, often concerned with subjects having substantial public interest.

- TECHNICAL TRANSLATION. Englishlanguage translations of foreign scientific and technical material pertinent to NASA's mission.

Specialized services that complement the STI Program Office's diverse offerings include creating custom thesauri, building customized data bases, organizing and publishing research results... even providing videos.

For more information about the NASA STI Program Office, see the following:

- Access the NASA STI Program Home Page at http://www.sti.nasa.gov

- E-mail your question via the Internet to help@sti.nasa.gov

- Fax your question to the NASA Access Help Desk at (301) 621-0134

- Telephone the NASA Access Help Desk at (301) 621-0390

- Write to: NASA Access Help Desk NASA Center for AeroSpace Information 7121 Standard Drive Hanover, MD 21076 
NASA/TM-2000-209810

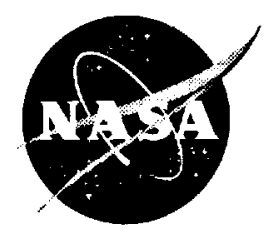

\section{The NASA Aviation Safety Program: Overview}

Jaiwon Shin

Glenn Research Center, Cleveland, Ohio

Prepared for the

45th International Gas Turbine and Aeroengine Technical Congress,

Exposition and Users Symposium

sponsored by the American Society of Mechanical Engineers

Munich, Germany, May 8-11, 2000

National Aeronautics and

Space Administration

Glenn Research Center 
Available from

NASA Center for Aerospace Information 7121 Standard Drive

Hanover, MD 21076

Price Code: A03
National Technical Information Service 5285 Port Royal Road Springfield, VA 22100 Price Code: A03 


\title{
THE NASA AVIATION SAFETY PROGRAM: OVERVIEW
}

\author{
Jaiwon Shin \\ National Aeronautics and Space Administration \\ Glenn Research Center \\ Cleveland, Ohio 44135 \\ Phone: (216) 433-8714 \\ Fax: (216) 433-2645 \\ E-mail: Jaiwon.Shin@grc.nasa.gov
}

\begin{abstract}
In 1997, the United States set a national goal to reduce the fatal accident rate for aviation by $80 \%$ within ten years based on the recommendations by the Presidential Commission on Aviation Safety and Security. Achieving this goal will require the combined efforts of government, industry, and academia in the areas of technology research and development, implementation, and operations. To respond to the national goal, the National Aeronautics and Space Administration (NASA) has developed a program that will focus resources over a five year period on performing research and developing technologies that will enable improvements in many areas of aviation safety. The NASA Aviation Safety Program (AvSP) is organized into six research areas: Aviation System Modeling and Monitoring, System Wide Accident Prevention, Single Aircraft Accident Prevention, Weather Accident Prevention, Accident Mitigation, and Synthetic Vision. Specific project areas include Turbulence Detection and Mitigation, Aviation Weather Information, Weather Information Communications, Propulsion Systems Health Management, Control Upset Management, Human Error Modeling, Maintenance Human Factors, Fire Prevention, and Synthetic Vision Systems for Commercial, Business, and General Aviation aircraft. Research will be performed at all four NASA aeronautics centers and will be closely coordinated with Federal Aviation Administration (FAA) and other government agencies, industry, academia, as well as the aviation user community. This paper provides an overview of the NASA Aviation Safety Program goals, structure, and integration with the rest of the aviation community.
\end{abstract}

\subsection{INTRODUCTION}

The worldwide commercial aviation major accident rate (as judged by hull losses per million departures) has been nearly constant over the past 2 decades. Although the rate is very low, increasing traffic over the years has resulted in the absolute number of accidents also increasing. The worldwide demand for air travel is expected to increase even further over the coming 2 decades-doubling or tripling by 2017 with the requirement for $\$ 1$ trillion in new aircraft deliveries. Without an improvement in the accident rate, such a traffic volume would lead to 50 or more major accidents a year-a nearly weekly occurtence (Fig. I). Given the very visible, damaging, and tragic effects of even a single major accident, this number of accidents would clearly have an unacceptable impact upon the public's confidence in the aviation system and impede the anticipated growth of the commercial air-travel market.

The safety of the general aviation (GA) system is also critically important. The current GA accident rate is many times greater than that of scheduled commercial transport operations. With the GA market also poised to grow significantly in future years, safety considerations must be removed as a barrier if this growth is to be realized.

To aggressively address these issues, President Clinton announced in February 1997 a national goal to reduce the fatal accident rate for aviation by 80 percent within 10 years. This national aviation safety goal is an ambitious and clear challenge to the aviation community. NASA immediately responded with a major program planning effort to define the appropriate research to be conducted by the Agency. This effort was initiated by the NASA Aviation Safety Investment Strategy Team (ASIST), which sponsored four industry- and government-wide workshops to define research needs. The planning effort lasted from February 1997 to April 1997 , and involved over 100 industry, government, and academic organizations (Fig. 2). 


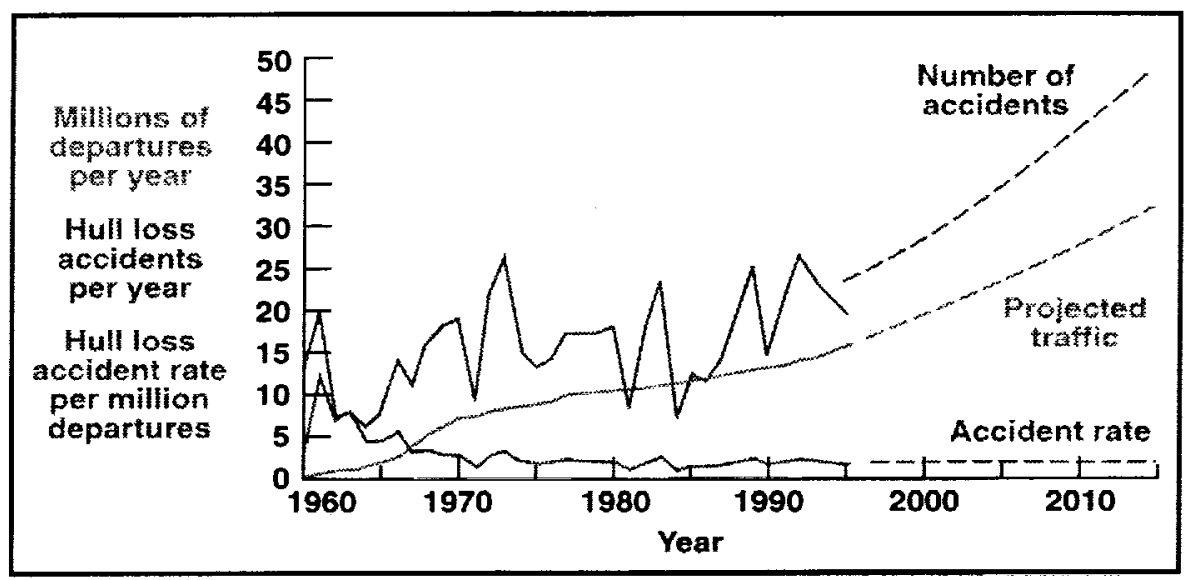

Figure 1. Projected Air Traffic Growth and Number of Accidents

(Source: The Boeing Company)

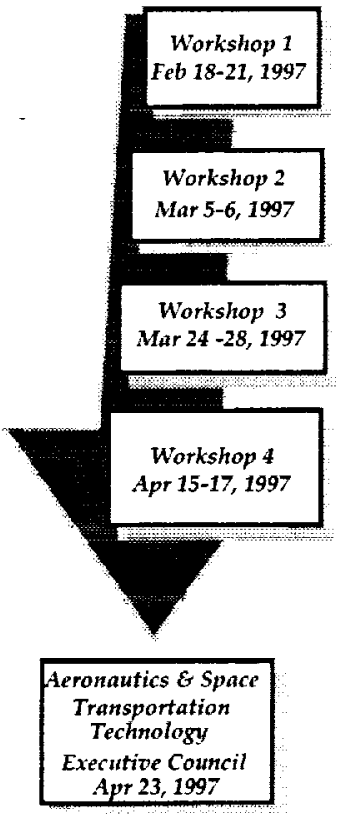

Industry Input; Identify Major Accident Causes \& Issues

Underlying

Problems

Solutions

Integrated

Solution Set

E Investment

Options

\section{Five ASIST Sub-Teams Formed which produced 58 prioritized recommended investments}

\section{These 58 were grouped into 23 Planning Elements in Three Investment Areas}

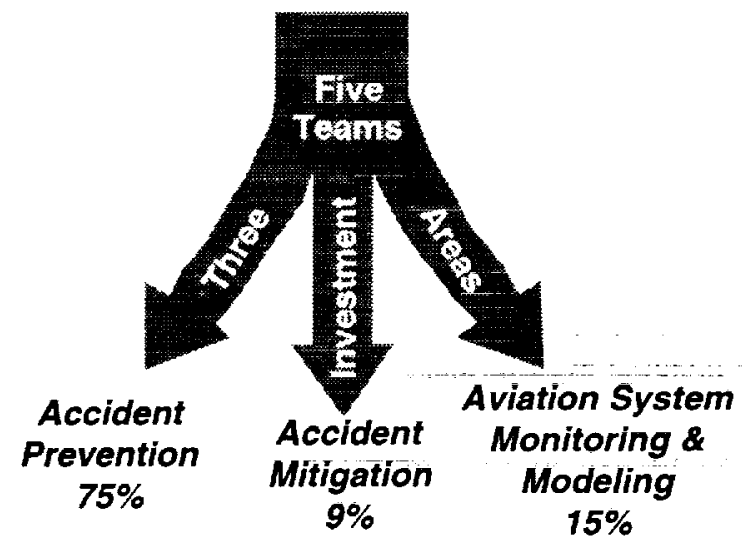

Figure 2. NASA Aviation Safety Investment Strategy Team (ASIST) Process

The ASIST recommendations provided the foundation and rational for formulation of the NASA Aviation Safety Initiative. The Aviation Safety Initiative is a combination of redirected Research and Technology (R\&T) Base activities and the AvSP, as a major new program. NASA R\&T Base programs enhance the foundation to the safety activities with tools and insight to fundamental principles, such as data sharing, human factors, human/system interface, weather hazards and structural integrity. The AvSP will provide research and technology products needed to help the Federal Aviation Administration (FAA) and the aerospace industry achieve the President's challenge to improve aviation safety in the coming decade and then move even further to a far-reaching challenge. NASA's Strategic Plan, which guides the formulation of such programs, includes a "Pillar One" enabling technology goal "to reduce the aircraft accident rate by a factor of 5 in 10 years and by a factor 10 within 25 years."

The NASA approach for contributing to the national goal is to develop and demonstrate technologies and strategies to improve aviation safety by reducing both aircraft accident and fatality rates. R\&T development will address accidents involving hazardous weather, controlled flight into terrain, accidents and incidents 
caused by human error, and mechanical or software malfunctions. The safety program will emphasize not only accident rate reduction but also a decrease in injuries and fatalities when accidents do occur. The program will also develop and integrate information technologies needed to build a safer aviation system-to support pilots and air traffic controllers-as well as provide information to assess situations and trends that might indicate unsafe conditions before they lead to accidents. The focus of each program element is the development of prevention, intervention, or mitigation strategies aimed at one or more causal, contributory, or circumstantial factors associated with aviation accidents. The program will give high priority to strategies that address factors determined to be the largest contributors to accident and fatality rates as well as those that address multiple classes of factors.

The AvSP management team will work as partners with the FAA in implementing the program and will maintain close coordination with the Department of Defense (DoD) and other government agencies. Additionally, the program will work in concert with the full spectrum of commercial, rotorcraft, and general aviation industry manufacturers, suppliers, and operators in implementing this effort.

\title{
NOMENCLATURE
}

\author{
ASIST Aviation Safety Investment Strategy Team \\ CAST Commercial Aviation Safety Team \\ CFIT Controlled Flight Into Terrain \\ GA General Aviation \\ SRTM Shuttle Radar Topography Mission
}

\subsection{PROGRAM GOALS AND OBJECTIVES}

The goal of the AvSP is derived from the NASA Aero-Space Technology Enterprise Strategic Goal, which in turn is derived from the President's National goal:

NASA Aero-Space Technology Enterprise Strategic Goal on Aviation Safety: Reduce the aircraft accident rate by a factor of 5 within 10 years and by a factor of 10 within 25 years.

NASA Aviation Safety Program Goal: Develop and demonstrate technologies that contribute to a reduction in aviation accident and fatality rates by a factor of 5 by year 2007 and by a factor of 10 by year 2022 .

The AvSP runs from FY 2000 through FY 2004 and focuses primarily on providing technologies that enable to the 10-year goal. Subsequent Aviation Safety Initiative programs will focus primarily on the 25 -year goal.

The program has been divided into three investment areas in order to achieve the goals: Accident Prevention, Aviation System Monitoring and Modeling, and Accident Mitigation (Fig. 2). These three investment areas are supported by objectives and associated critical technology deliverables:

(1) Eliminate targeted accident categories;

(2) Increase accident survivability; and

(3) Strengthen safety technology foundation

Eliminating targeted accident categories will be accomplished through key technical developments: delivery of precision approach and landing technologies and displays that provide intuitive guidance and piloting decision support worldwide, at any runway, at any airport, for both general and commercial aviation; affordable technologies and systems for the data-linked communication and on-board graphical display of critical aviation weather information both nationally and internationally; turbulence modeling and detection technologies that allow for predictive warning and/or avoidance of severe turbulence encounters; and synthetic vision technologies and implementable, demonstrated system concepts that provide immediate, clear-day equivalent visual awareness and avoidance of worldwide terrain and obstacles in any weather or light condition.

The accident survivability objective is to reduce fatalities in those cases where accidents do occur. Advanced structural and material designs that demonstrate greatly improved crash survivability and fire hazard mitigation are the critical deliverables supporting the accident survivability objectives. 
The overall safety of the aviation system is based on the strength of its foundation. This foundation consists of the total aviation infrastructure, made up of aircraft, ground facilities, equipment, people, and procedures. ASIST recommendations supported the need to invest in aviation system modeling, validated humanerror assessment methodologies that allow system designs and procedures to be analyzed for error susceptibility, and integrated aviation system monitoring tools that allow regular operational assessments to identify unsafe trends before they become accidents.

\subsection{PROGRAM MISSION SUCCESS CRITERIA}

Based on the AvSP goal, the criteria for program mission success are the development of technologies that, when implemented by the aviation community, will contribute to a reduction of the civil aviation accident rates. Baseline data are for the period 1990-1996 and are obtained from the National Transportation Safety Board (NTSB) Accident Statistics for U.S. Civil Aviation, which are broken out by Federal Aviation Regulations (FAR) Parts 121, 135, and 91. International data will be obtained from sources such as the International Civil Aviation Organization (ICAO) and Air Claims (an aviation insurance database). Mission success criteria evaluations will include projected percentages of accident reduction based upon analysis of NTSB accident statistics and other relevant aviation safety data.

The measure of the success of the technology development will be based on the demonstration of achievement of sufficient maturity of the technology to enable partners and customers to adopt and complete the technology application. The technology maturation process will be assessed using defined Technology Readiness Levels (TRL's). In general, the AvSP will develop technologies to TRL 6 (demonstrate a technology with a system or subsystem model or prototype in a relevant environment).

Along with the technology development efforts will be ongoing activities by NASA to promote the implementation of program outputs into the aviation community. NASA researchers will stay involved to help program "outputs" become "outcomes." NASA will work with, and rely on, industry and FAA partners to implement these technologies. The program is implementing an analysis process to determine projected technology impacts on aviation safety. Program benefits will be identified through systems analysis where the input is defined as project technology products. The results of these analyses are to be documented and reported at each of the Program Assessment milestones in FY '00, '02 and '04. In the absence of a fully completed assessment, estimated impacts have been identified and will be updated as the technology assessment process and input data becomes more refined. The initial program mission success criteria are to produce:

- Human-error assessment methodologies that allow system designs and procedures to be analyzed for error susceptibility-validated in piloted simulation

- Health and Usage Monitoring technologies that enable real time and trending status of critical on-board aircraft systems-demonstrated in flight

- Affordable technologies and systems for the data-linked communication and on-board graphical display of critical aviation weather information both nationally and internationally-demonstrated in flight

- Turbulence modeling and detection technologies that allow for predictive warning and/or avoidance of severe turbulence encounters-demonstrated in flight

- Synthetic Vision technologies and implementable, demonstrated system concepts that provide immediate, clear day-equivalent visual awareness and avoidance of worldwide terrain and obstacles in any weather or light condition-demonstrated in flight

- Precision approach and landing technologies and displays that provide intuitive guidance and piloting decision support worldwide, at any runway, at any airport, for both general and commercial aviation-demonstrated in flight

- Advanced structural and material designs that demonstrate $20-40 \%$ improvement in crash survivability and fire hazard mitigation

- Integrated aviation system monitoring tools and infrastructure design accessible both nationally and internationally, allowing regular operational assessments to identify unsafe trends before they become accidents-operational at least two major airlines

The AvSP will assess potential impacts and track the status of projected technology impacts delineated in Table 1. In addition to these metrics, predictive information, such as the identification and tracking of "accident precursors"-incidents and off-nominal events and trends that may lead to accidents-will be developed, categorized, and monitored.

Consistent with the measures proposed by the FAA Office of Research and Acquisition, the accident rate baseline will be established with data averaged over the timeframe from 1990 to 1996. 
Table 1.-Framework for Projecting Technology Impact

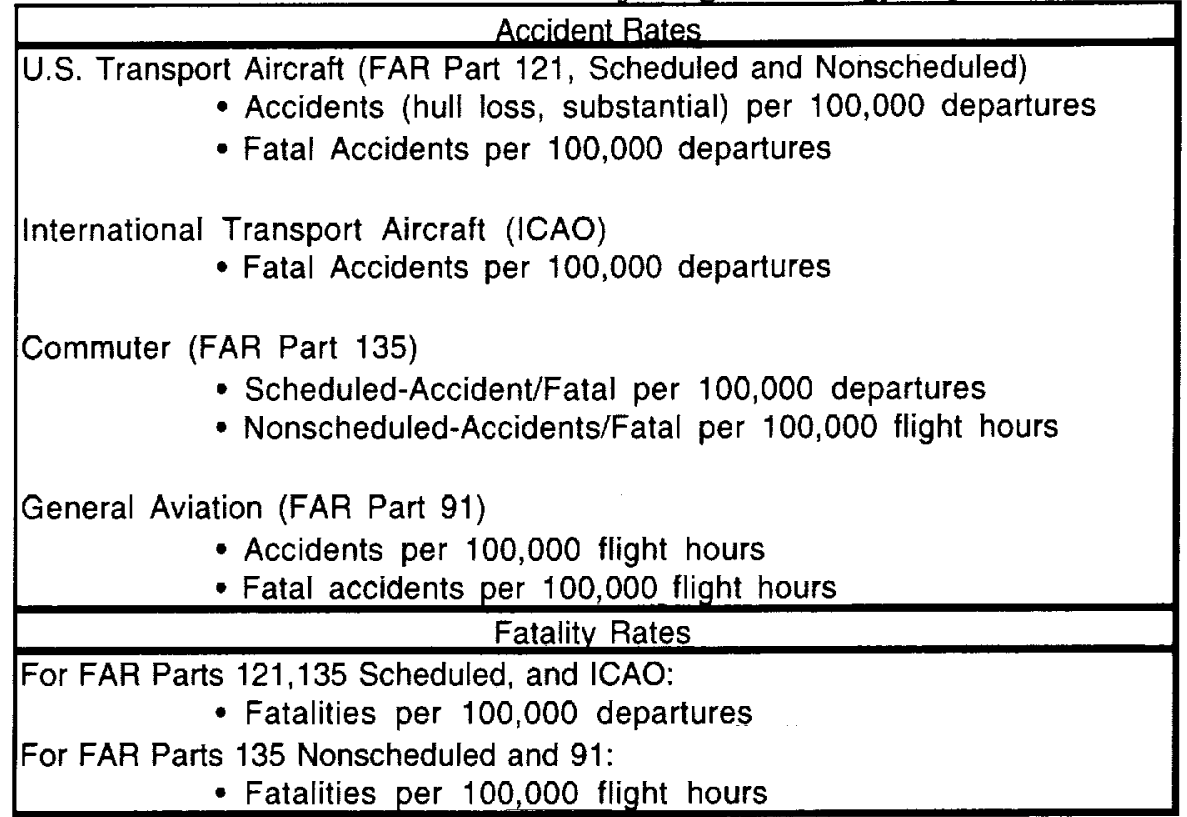

\subsection{PROGRAM ORGANIZATION}

The AvSP Office is at NASA LaRC, which has Lead Center responsibilities for the Program. The AvSP Office is led by the AvSP Program Director, who reports to the LaRC Director. The six Projects are led by managers from multiple NASA Centers (Fig. 3).

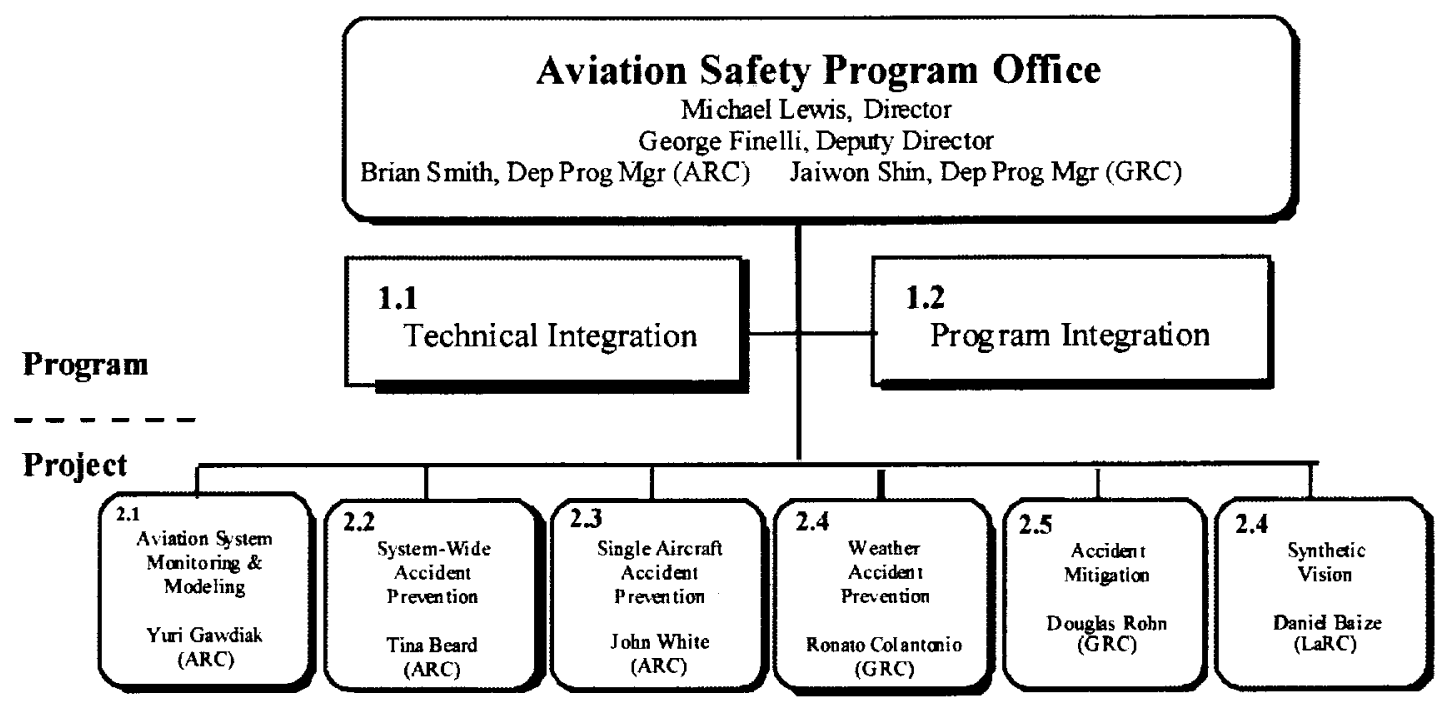

Figure 3. Program Organization Structure 


\subsection{PROGRAM DESCRIPTION}

The Program's technology developments are incorporated in the six projects described in the following section.

\subsection{Aviation System Monitoring and Modeling}

The Aviation System Monitoring and Modeling (ASMM) goal is to provide decision makers in air carriers, air traffic management, and other air service providers with regular, accurate, and insightful measures of the health, performance, and safety of the National Aviation System (NAS). ASMM outputs will also provide technology and procedure developers with reliable predictions of the system-wide effects of the changes they are introducing into the aviation system. This capability will enable definition of operational and safety trends and the identification of developing conditions that could compromise NAS safety. It will also allow an industry-wide, and eventually a worldwide, proactive approach to identification and alleviation of life-threatening aviation conditions and events.

The three-fold approach of ASMM is to (I) develop systems and tools to provide data pertaining to all aspects of the NAS, (2) develop tools to analyze and characterize the NAS and identify situations that may indicate changes to levels of safety, and (3) provide worldwide capabilities to obtain, access, and share relevant data on the NAS to the aviation community. The key attribute of all tools developed is that they will facilitate efficient and insightful analyses of all relevant data to identify causal factors, accident precursors, and unsuspected features in the data collected pertaining to the health, performance, and safety of the NAS.

\subsection{System-Wide Accident Prevention}

The System-Wide Accident Prevention (SWAP) goal is to address aviation safety issues associated with human error and procedural noncompliance. Human error is attributed as a factor in 60 - to 80 -percent of aviation accidents, depending on estimate sources. Reducing or mitigating human error effects will result in significant aviation accident rate reductions. This element will pursue research activities in the following areas: (1) human error modeling, (2) maintenance human factors, and (3) training.

Human error modeling will develop predictive capabilities to identify likely error vulnerabilities in human/system operation. This modeling will involve developing better understanding of the contexts in which errors occur, their potential causes, and candidate solutions to reduce or mitigate their effects.

Maintenance human factors will develop products that support improved maintenance operations. Maintenance error is often latent and thus difficult to identify, track, and analyze. The situation is exacerbated by human factors issues that arise from numerous changes in maintenance operations. Document design tools provide a direct defense against procedural errors by aiding maintenance engineers and managers in systematically evaluating and enhancing maintenance procedures and by providing maintenance technicians a means of feeding back improvements to the organization. Maintenance resource management (MRM) training guidance and tools help industry to establish standards and performance metrics for MRM training and to focus and direct the development of training materials that address high priority human factors domains that are critical to maintenance safety.

Training will develop more effective training procedures and aids. Better tools will be provided to enable crews to reduce errors with existing systems, to safely conduct a wide range of normal operations, and to effectively manage unanticipated abnormal situations. Training, and thus safety, can be improved by developing better methods for conveying knowledge and skills and by elucidating the root causes of human error. These improvements will be effected through the development of specific training curricula, simulations, and crew performance measurement techniques.

\subsection{Single Aircraft Accident Prevention}

The Single Aircraft Accident Prevention (SAAP) goal is to develop and support the implementation of aircraft specific technologies that will reduce the fatal accident rate in accordance with program goals. Two accident categories that the SAAP Project will directly address are loss of control in flight and aircraft sys= tem/component failures. Based upon accident data, loss of control in flight is a leading category of fatal accidents. Conversely, while system failures are not often cited as the primary cause of an accident, a system failure or malfunction is often cited across accident categories as the initiating occurrence that set off the 
sequence of events which led to the accident. Additionally, as systems--and, in particular, flight critical systems--become more integrated and complex, current processes for certification of these systems will become inadequate. SAAP will support the development of new methods to efficiently validate and verify complex flight critical systems. Human factor considerations cut across all these categories and concerns and will be an integral part of the technology development process. Vehicle classes addressed in the SAAP element are transports, rotorcraft, and GA. This element will pursue research activities in the following technology areas:

(I) vehicle health management and flight critical systems design, (2) propulsion health management, and (3) control upset prevention and recovery.

Vehicle health management and flight critical systems design will develop intervention techniques that detect system component degradation trends before they result in catastrophic failures. Formal methods for certification of complex flight critical system will also be developed. Similarly, propulsion health management will focus on development of propulsion system specific technologies intended to detect potential failures before they become catastrophic.

Control upset prevention and recovery will develop technologies to prevent loss-of-control-type accidents due to aircraft upset after inadvertently entering an extreme or abnormal flight attitude. Loss of Control as considered by this element may be due to turbulent weather, pilot disorientation, or a system failure. Close coordination with other projects is required to ensure that the technology development activities for control system failure detection, pilot interfaces, and information transfer techniques are synergistic.

\subsection{Weather Accident Prevention}

The Weather Accident Prevention (WxAP) goal is to develop and support the implementation of technologies that will reduce the fatal accident rate induced by weather hazards. This reduction is to be accomplished for commercial, general aviation, and rotorcraft sectors, given projected capacity increases and while either maintaining or improving efficiency. Weather is a factor in approximately 30 percent of aviation accidents. In addition, the majority of CFIT and GA "loss of control" accidents are considered to be visibilityinduced crew error, where better weather information or better pilot vision would have been a substantial mitigating factor. The key objective of this research element is to provide complete weather information and situational awareness to pilots and ground operators in any atmospheric condition that affects the operation and safety of an aircraft. The WxAP element will pursue research activities in the following technology areas: (1) aviation weather information, (2) weather information communications, and (3) turbulence detection and mitigation.

Aviation weather information distribution (AWIN) and presentation will develop technologies that provide high fidelity, timely, and intuitive information to pilots, dispatchers, and Air Traffic Control (ATC) to enable the detection and avoidance of atmospheric hazards.

The Weather Information Communication element will develop enabling communication technologies and architectural concepts that will provide accurate and timely weather information to the cockpit for both national and international flight.

Turbulence detection and mitigation will enhance forecasting tools by developing a total detection system and flight control techniques to mitigate the consequence of upsets due to all types of turbulence encounters, including clear air turbulence (CAT).

\subsection{Accident Mitigation}

The Accident Mitigation (AM) goal is to develop, enable, and promote the implementation of technologies that will increase the human survival rate in survivable accidents, and to prevent in-flight fires. To reach the NASA AvSP goal of reducing fatalities, the number of survivors must be increased in accidents that are of the severity level where some, but not all, passengers survive. Data show that for transports, half of all accidents involve serious injury and/or fatality, and half of those accidents are survivable (i.e., greater than three survivors). Fatalities are the result of impact factors, fire/smoke, or some combination of both (e.g., nonfatal injuries that prevent escape and lead to being overcome by smoke). Further, in-flight fires account for 5 percent of all fatalities. Based on this background, the overall approach in AM is to reduce the physical crash dynamics hazards, minimize fire effects in order to allow more time for evacuation, and reliably detect and suppress in-flight fires. The AM element is targeted to all classes of aircraft. In the rotorcraft community, great progress has been made in improving rotorcraft crashworthiness. Fuel-fire prevention is presently limited to aircraft using jet-A fuel. The AM project activities will address the following areas: (1) systems approach to crashworthiness (including crash resistant fuel systems) and (2) fire prevention. 
Systems approach to crashworthiness will seek to limit hazards by focusing on the impact and crash dynamics factors in accidents. A systems approach is required because of the significant interaction between contributing elements. Crash survivability is a function of impact flight conditions, impact surface, airframe response, seat response, restraint system performance, and occupant response. Thus, the objectives are to improve crashworthiness by a systems approach that includes validated analysis methodology, new structural concepts and materials, safer cabin interiors, advanced restraint equipment, and design and injury criteria to enhance crash safety. Additionally, the objective to minimize post-crash fires will be approached by developing technology (and leveraging DoD technology) to minimize fuel spillage in a crash situation.

Fire prevention will develop, leverage, and demonstrate technology for limiting hazards due to fire. Firerelated accident mitigation falls into two categories: post-accident and in-flight. In the former, humans are overcome by smoke (or the fire itself) before they can escape. Such fires are often fed by pools of spilled fuel on the ground, and involve combustion of cabin interior materials as well. The latter category involves fuelrelated explosions, as well as detection and suppression of fires within the cargo hold or cabin. Preliminary data indicate that present detection technology involves an unacceptably high rate of false alarms. Thus, the objectives are to prevent post-crash fuel-fed fires and in-flight fuel-related fires (explosions) via fuel modifications or inerting, minimizing the fire-heat release from cabin materials, and reliably detecting and suppressing cargo compartment fires.

\subsection{Synthetic Vision}

Limited visibility is the single most critical factor affecting both the safety and capacity of worldwide aviation operations. In commercial aviation, over 30 percent of all fatal accidents worldwide, and the leading cause of total fatalities, are categorized as CFIT--accidents in which a functioning aircraft impacts terrain or obstacles that the flight crew could not see. In addition, the largest general aviation accident category is 'Continued Flight into Instrument Meteorological Conditions', in which low-experience pilots continue to fly into deteriorating weather and visibility conditions and either collide with unexpected terrain or lose control of the vehicle because of the lack of familiar external cues. Finally, the single largest factor causing airport flight delays is the limited runway capacity and increased air traffic separation distances resulting when visibility conditions fall below visual flight rule operations. Synthetic Vision technology will allow these visibility problems to be addressed for the first time with a visibility solution-making every flight the equivalent of a clear daylight operation. Fully implemented, successful synthetic vision technologies will be a revolutionary improvement in aviation safety and utility.

The promise of synthetic vision has made its development a top recommendation of the FAA/NASA/ CAST, the Flight Safety Foundation's Approach and Landing Task Force, and other key analyses. A synthetic vision approach utilizes a stored digital terrain database and Global Position Systems (GPS) position information to create a high-resolution 3-D moving image. Synthetic Vision displays are unlimited in range, unaffected by atmospheric conditions, and require only computer memory and processing to function. The capability of synthetic vision is limited only by the resolution and accuracy of the terrain database. Over the past 5 years, a number of organizations, including NASA, have demonstrated synthetic vision-based flight, landings, and taxi operations in research aircraft. Digital data links and displays of the positions and paths of airborne and ground traffic have also been demonstrated.

The Aviation Safety Program's Synthetic Vision Project aims to develop the practical and certifiable basis for a cockpit system utilizing a high-resolution digital terrain data base and augmented, if necessary, by onboard imaging sensors. The rapid emergence of reliable GPS position information and precise digital terrain maps, including data from the Shuttle SRTM mission, made this approach capable of true all-weather performance as well as extremely low cost, low maintenance operations. The AvSP's objective is to prove this technology practical not just as a research demonstration, but as a viable, implementable capability.

\subsection{PARTNERSHIP}

The AvSP will bring customers into all phases of the program as partners. Current customers and partners for the Aviation Safety Program include the FAA, airlines, operators, airframe manufacturers, engine companies, airframe systems manufacturers, material suppliers, DoD, and academia. Special emphasis has been placed on establishing a strong partnership relationship with the FAA as the FAA is primarily responsible for the overall safety of the U.S. national aviation system. 
The investment strategy process, recommended by ASIST, relied on customer involvement and input to identify critical thrusts. Subsequent workshops, again with customer involvement, provided more detailed analysis and insight to critical safety areas and potential solutions. Just as the research and development planning process involved customers, the implementation process will be planned with NASA involvement, as appropriate. For each program element and project, a "partnering" team will be established to plan and conduct the research and eventually to facilitate technology implementation.

The AvSP will also remain sensitive to industry requirements through strategic involvement with the Commercial Aviation Safety Team (CAST). CAST is a group of senior Government and Industry commercial aviation leaders whose goal is to form a national safety agenda and a plan for making commercial aviation safer. CAST charters Joint Safety Analysis Teams (JSAT's) to analyze specific safety issues and recommend intervention opportunities. The CAST/JSAT approach has been adopted as a key aspect of the FAA's "Safer Skies" Initiative. A similar organization has been formed for General Aviation called the General Aviation Joint Steering Committee (GAJSC).

To ensure that NASA and FAA safety research and development activities are appropriately coordinated, a NASA/FAA Joint Working Group has been established. Participants in this group include senior managers from NASA and FAA Headquarters and the AvSP Program Director.

The Aviation Safety Program will emphasize rapid and effective dissemination of the technology to the U.S. industry. Technology transfer mechanisms depend on the maturity of the technology. A variety of technology transfer mechanisms will be employed. The most important is direct involvement of the users in the formulation of the program described in this plan and direct contract of R\&D. AvSP resources fund R\&D contracts and grants, which help ensure direct transfer of technology to the US.industry and thus increase the likelihood of direct input into near-term products. Technology exchange will also occur among the participants through special technical working group meetings. Presentations at technical conferences sponsored by the American Institute of Aeronautics and Astronautics, American Society of Mechanical Engineers, and other similar professional societies will be limited to discussion of non-competitively sensitive information. Other methods of technology transfer include technical reports, cooperative programs, and personnel exchanges between NASA, industry and other government agencies through memoranda of agreement, and technical demonstrations at NASA and user facilities. The AvSP will work closely with the Technology Commercialization Office at the respective Centers to help communicate technology commercialization opportunities to a wide range of potential users.

\subsection{SUMMARY}

This paper provided an overview of the NASA Aviation Safety Program goals, structure, technical content, and integration with the rest of the aviation community. It is important to note that NASA will be developing technologies to enable manufacturers and operators to reduce the fatal aircraft accident rates when the technologies are implemented. In order to ensure timely and effective implementation of the technologies, NASA will be coordinating its R\&T efforts with the FAA at an unprecedented level of intensity and focus. NASA AvSP will also actively engage with manufacturers and operators to understand and work on the right industry requirements through CAST, GAJSC, and other forums. 


\section{REPORT DOCUMENTATION PAGE}

Pubtic reporting burden for this collection of information is estlmated to average 1 hour per response, including the time for reviewing instructions, searching existing data sources, gathering and maintalning the data needed, and completing and reviewing the collection of information. Send comments regarding this burden estimate or any other aspect of this Davis Highway, Suite 1204, Arlington, VA 22202-4302, and to the Office of Management and Budget, Paperwork Reduction Project (0704-0188), Washington, DC 20503.

\begin{tabular}{|l|l|l}
\hline 1. AGENCY USE ONLY (Leave blank) & $\begin{array}{c}\text { 2. REPORT DATE } \\
\text { March } 2000\end{array}$ & $\begin{array}{r}\text { 3. REPORT TYPE AND DATES COVERED } \\
\text { Technical Memorandum }\end{array}$
\end{tabular}

4. TITLE AND SUBTITLE 5. FUNDING NUMBERS

The NASA Aviation Safety Program: Overview

6. AUTHOR(S)

Jaiwon Shin

National Aeronautics and Space Administration

John H. Glenn Research Center at Lewis Field

Cleveland, Ohio 44135-3191

WU-577-90-20-00

9. SPONSORING/MONITORING AGENCY NAME(S) AND ADDRESS(ES)

National Aeronautics and Space Administration

Washington, DC 20546-0001

8. PERFORMING ORGANIZATION REPORT NUMBER

E-12119

10. SPONSORINGMONITORING AGENCY REPORT NUMBER

NASA TM-2000-209810

11. SUPPLEMENTARY NOTES

Prepared for the 45th International Gas Turbine and Aeroengine Technical Congress, Exposition and Users Symposium sponsored by the American Society of Mechanical Engineers, Munich, Germany, May 8-11, 2000. Responsible person Jaiwon Shin, organization code 2500, (216) 433-8714.

12a. DISTRIBUTION/AVAILABILITY STATEMENT

12b. DISTRIBUTION CODE

Unclassified - Unlimited

Subject Category: 07

Distribution: Nonstandard

This publication is available from the NASA Center for AeroSpace Information, (301) 621-0390.

13. ABSTRACT (Max/mum 200 words)

In 1997, the United States set a national goal to reduce the fatal accident rate for aviation by $80 \%$ within ten years based on the recommendations by the Presidential Commission on Aviation Safety and Security. Achieving this goal will require the combined efforts of government, industry, and academia in the areas of technology research and development, implementation, and operations. To respond to the national goal, the National Aeronautics and Space Administration (NASA) has developed a program that will focus resources over a five year period on performing research and developing technologies that will enable improvements in many areas of aviation safety. The NASA Aviation Safety Program (AvSP) is organized into six research areas: Aviation System Modeling and Monitoring, System Wide Accident Prevention, Single Aircraft Accident Prevention, Weather Accident Prevention, Accident Mitigation, and Synthetic Vision. Specific project areas include Turbulence Detection and Mitigation, Aviation Weather Information, Weather Information Communications, Propulsion Systems Health Management, Control Upset Management, Human Error Modeling, Maintenance Human Factors, Fire Prevention, and Synthetic Vision Systems for Commercial, Business, and General Aviation aircraft. Research will be performed at all four NASA aeronautics centers and will be closely coordinated with Federal Aviation Administration (FAA) and other government agencies, industry, academia, as well as the aviation user community. This paper provides an overview of the NASA Aviation Safety Program goals, structure, and integration with the rest of the aviation community.

\section{SUBJECT TERMS}

Aviation Safety Program; Fatal Accident Rate; Weather Accident Prevention; Accident Mitigation; Propulsion Systems Health Management

\begin{tabular}{|c|c|}
\hline $\begin{array}{c}\text { 17. SECURITY CLASSIFICATION } \\
\text { OF REPORT }\end{array}$ & $\begin{array}{c}\text { 18. SECURITY CLASSIFICATION } \\
\text { OF THIS PAGE } \\
\text { Unclassified }\end{array}$ \\
Unclassified
\end{tabular}

19. SECURITY CLASSIFICATION OF ABSTRACT Unclassified
15. NUMBER OF PAGES 17

16. PRICE CODE $\mathrm{A03}$

20. LIMITATION OF ABSTRACT

Standard Form 298 (Rev. 2-89) Prescribed by ANSI Std. Z39-18 298-102 